Nota de pesquisa/ Research note

\title{
REGISTRO DE Gracilinanus agilis (MARSUPIALIA, DIDELPHIDAE) PARASITADO POR Metacuterebra apicalis (DIPTERA, CUTEREBRIDAE) NO CERRADO DE BRASÍLIA, DISTRITO FEDERAL, BRASIL
}

José Roberto Pujol-Luz (1), André Faria Mendonça ${ }^{(2)}$

\& Raimundo Henriques ${ }^{(2)}$

\begin{abstract}
A record of Gracilinanus agilis (Marsupialia, Didelphidae) parasited by Metacuterebra apicalis (Diptera, Cuterebridae) in the cerrado of Brasília, Distrito Federal, Brazil - The first report of infection caused by maggots of the botfly Metacuterebra apicalis (GuérinMéneville) on miceopossums Gracilinanus agilis (Burmeister) is presented. The examined individuals collected in the cerrado vegetation in Brasilia, DF, Brazil, showed infections in ventral area of the body, around genital organs. Two botflies (male and female) emerged in a period of 29 to 31 days.
\end{abstract}

Key words: Parasitism, myiasis, Cuterebridae, Marsupialia, cerrado

(1) Departamento de Zoologia, (2) Departamento de Ecologia, Instituto de Ciências Biológicas, Universidade de Brasília, CEP: 70910-900 Brasília, Brasil. E-mail: jrpujol@unb.br.

Com auxílio do CNPq e CAPES.

Recebido em: 08/07/2004.

Aceito em: 02/09/2004. 
Os Cuterebrídeos são moscas com distribuição restrita ao Novo Mundo e são bem conhecidas por parasitarem principalmente roedores, lagomorfos e primatas (Guimarães \& Papavero, 1999).

Larvas de cuterebrídeos do gênero Metacuterebra Bau são endoparasitas de tecidos cutâneos de várias espécies selvagens de mamíferos (Pereira 1994; Vieira 1993). Recentemente, Guimarães \& Papavero (1999) apresentaram uma revisão dos Cuterebridae da América do Sul, fornecendo um excelente banco de dados bibliográfico e atualizando as informações taxonômicas disponíveis sobre este grupo de moscas.

Guimarães \& Papavero (1999) listaram 15 espécies de Metacuterebra incluindo diagnoses, registros de distribuição e uma chave para as espécies da América do Sul. Das espécies citadas pelos autores, 8 tem como hospedeiro natural alguma espécie de marsupial. Metacuterebra apicalis (Guérin-Méneville) foi registrada como parasita de Marmosa mitis isthimica Goldman, no Panamá e Metachirus nudicaudatus (E. Geoffroy), no Brasil, Estado de São Paulo (Bossi \& Bergallo, 1992; Guimarães \& Papavero, 1999).

Gracilinanus agilis (Burmeister) é um marsupial arborícola noturno pertencente à tribo Marmosini e se alimenta principalmente de frutos e insetos. Essa espécie abriga-se durante o dia em cavidade de troncos e emaranhados de galhos ou cipós no alto das árvores. Apresenta ampla distribuição no Brasil Central e ocorre principalmente em formações florestais (Eisenberg \& Redford, 1999).

A infestação de $M$. apicalis foi observada pela primeira vez em $G$. agilis capturados com o auxílio de armadilhas "Sherman" $(23 \times 9 \times 8 \mathrm{~cm})$ colocadas no solo e no alto em um fragmento natural de cerradão distrófico, que possui uma área de cerca de 3,2 ha e está localizado no Jardim Botânico de Brasília (1553'17'S, 4750'46”'S), a cerca de $25 \mathrm{~km}$ do centro da cidade, com uma área de aproximadamente 4.500 ha e altitude média de 1100 m (SEMATEC, 1994).

O cerradão é uma formação florestal, xeromórfica e semidecídua, com a altura do dossel variando de 8-12 metros e com 50-90\% de cobertura da copa. Estruturalmente, o cerradão possui três extratos bem divididos: 0 arbóreo, bem denso com as copas se tocando e compreendendo a faixa de 10-12 m de altura; o arbustivo, bem marcado, constituído principalmente por arbustos esclerófilos; e o herbáceo, pouco desenvolvido.

Foram registrados seis indivíduos de G. agilis e um de Oryzomys subflavus infestados, representando aproximadamente $9 \%$ do total ( $N=78$ 
indivíduos) de pequenos mamíferos capturados. Os indivíduos de G. agilis parasitados por $M$. apicalis ocorreram apenas durante a estação chuvosa e cinco dos seis indivíduos que apresentavam o parasita eram fêmeas jovens. Mesmo com o número amostral pequeno é possível que exista uma maior taxa de infestação de fêmeas para essa espécie.

A infestação ocorreu sempre na forma de cistos cutâneos na região ventral e o número de larvas variou de uma a três por indivíduo de $G$. agilis. Os indivíduos de G. agilis infestados apresentaram uma rápida recuperação e alguns recapturados cinco dias após a saída da larva apresentavam a ferida decorrente praticamente cicatrizada.

Dois adultos (1 macho e 1 fêmea) emergiram em laboratório. Após serem extraídas dos marsupiais, as larvas foram depositadas em recipientes de plástico com tampa vedada, sobre um substrato de serragem. As condições de umidade do recipiente foram mantidas molhando-se a serragem periodicamente. A emergência das imagos ocorreu entre 29 (fêmea) e 31 (macho) dias.

\section{Referências Bibliográficas}

Bossi, D.E.P. \& Bergallo, H.G., 1992. Parasitism by Cuterebrid Botflies (Metacuterebra apicalis) in Oryzomys nitidus (Rodentia: Cricetidae) and Metachirus nudicaudatus in a Southeastern Brasilian Rain Forest. J. Parasitol. 78:142-145.

Eisenberg, J.F. \& Redford, K.H., 1999. Mammals of the Neotropics. The Central Neotropics: Ecuador, Peru, Bolivia, Brazil. Chicago University Press, Chicago. 609 p.

Guimarães, J.H. \& Papavero, N., 1999. Myiasis in man and animals in the Neotropical Region. Bibliographic database. Editora Plêiade/ Fapesp. 308 p.

Pereira, L.A. 1994. Ecologia de mamíferos da Mata Atlântica: Parasitismo de Metacuterebra spp. (Diptera, Cuterebridae) em cinco espécies de pequenos mamíferos da Reserva Biológica de Poço das Antas (Mun. Silva Jardim, Rio de Janeiro). Flor. Amb. 1:86-90. 
SEMATEC. 1994. Jardim Botânico de Brasília. 26 p.

Vieira, E.M., 1993. Ocurrence and Prevalence of Bot Flies, Metacuterebra apicalis (Diptera: Ceterebridae), in Rodents of Cerrado from Central Brazil. J. Parasitol. 79:792-795. 